\title{
CONCERNING THE PROCESS OF THRUST FAULTING
}

\section{TERENCE T. QUIRKE}

University of Illinois

The following paper is offered as a contribution to the studies of low-angle faulting which have been led by the researches and teaching of Professor R. T. Chamberlin.

A comparison of this paper with previous publications, especially "Low-Angle Faulting," by R. T. Chamberlin and W. Z. Miller, ${ }^{\mathrm{I}}$ will show that the writer has followed Chamberlin in large measure. Most of the material here presented has really been anticipated in the article referred to, but a different manner of approach on some phases of the study is attempted, and the possibility is suggested that there may be a closer relationship between low- and high-angle thrust faults than is commonly accepted.

In rgro Chamberlin ${ }^{2}$ published his paper on the structure of the Appalachian Mountains in which he showed reason to believe that the part of the crust affected by deformation is a shallow, wedge-shaped mass about thirty miles deep and about nine hundred miles long. Willis, ${ }^{3}$ upon independent but similar arguments, suggested that the depth of the mass deformed in the uplift of the Cascades lies between thirty-seven and one-half and fifteen hundred miles.

So far as the writer knows, these conclusions have been accepted as sound, in spite of the fact that they appear to be fundamentally different from the prevalent notion that mountain folding is relatively shallow and that the deformable crust of the earth is of the

IJour. Geol., XXVI (I9I8), I-44.

${ }^{2}$ R. T. Chamberlin, "Appalachian Folds of Central Pennsylvania," Jour. Geol., XVIII (I910), 228-5I.

3 Bailey Willis, U.S. Geol. Surv., Prof. Paper No. 19 (1903), p. 97. 
character of a thin layer or sheet. In a later paper Chamberlin concludes as the result of his work in the Rocky Mountains that the western mountain mass has this generic difference from the eastern range in that it is composed of broadly folded members of very great depth as contrasted with severely folded and faulted members of less depth. Thus following Chamberlin, it seems that there are some cases of mountain folding in which the strains are relatively shallow as well as some cases in which deformation has been much deeper, which may support the theory that faulting and sharp folding may affect a shallow terrain at the same time that deeper parts of the crust are undergoing flow deformation. The observation of Daly ${ }^{2}$ that in south central British Columbia the overlying sediments are much more sharply folded than the underlying pre-Cambrian rocks gives further support to this general notion.

In attempting to analyze earth deformation it is natural, erroneously, to consider the deformed parts of the crust as comprising the whole members subjected to stress; whereas such parts are merely those portions of the structural member which failed. ${ }^{3}$ In consequence of this, it follows that it is a matter of considerable doubt as to what the nature and dimensions of the structual members may have been. So it comes about that most discussions are based upon an attempted analysis of the strains involved rather than upon the basis of controlling forces. And this is logical enough, in that here and there the strains remain clearly recorded, whereas the stresses and the nature of the members involved can only be inferred. Presumably, if we follow the traditional teachings, the compressive forces are caused by a more rapid decrease in volume of the inner part of the earth than can be accompanied by the solid shell without buckling or breaking, and consequently the whole shell of the earth constitutes the members concerned. However, the earth's crust is sharply divided into continental and oceanic members; whether these members are conceived to be

${ }^{I}$ R. T. Chamberlin, "The Building of the Colorado Rockies," Jour. Geol., XXVII (I9I9), 248.

${ }^{2}$ R. A. Daly, quoted by C. K. Leith, Structural Geology (1913), p. I 27.

${ }^{3}$ Cf. Chamberlin and Miller, op. cit., p. 2 r. 
segments or sectors, according to the older and the newer theories respectively, they act as individual components of a single member and as such are subject to separate analyses. Curved, rigid, sheetlike members under lateral compression fail in the center. Apparently the earth members fail by rupture and buckling at the ends or edges, ${ }^{\mathrm{I}}$ from which it follows, either that the conception of sheetlike members is erroneous, or that the members are not rigid bodies, or both. It is surely a fact that the earth members are not rigid under the conditions of mountain folding; the manner of their failure proves that beyond question. There is still a possibility that under some conditions the forces are transmitted through shell-like members, and that at other times the forces are distributed throughout deep earth sectors. It seems to be probable that both conditions have prevailed repeatedly at different times. Chamberlin's conclusion that the mountain ranges are of two generic types, one with deep and the other with shallow roots, supports this idea. But, however deep the strains may be, it is possible that there is so distinct a zone of shearing between the frangible, nearly rigid crust and the interior which is deformed by flow that the crustal part in any case fairly may be considered an individual member. It is probable that deep-seated strains affect a discontinuous member, plastico-rigid at depth, but more frangible toward the surface, ${ }^{2}$ wherefore the term "plasticofrangible," perhaps, might be used to denote the characteristic quality of the outer crust. Objections to these terms arise readily, especially by comparison with the terminology of other writers. T. C. Chamberlin prefers the term "elastico-rigid"' ${ }^{3}$ because that expression indicates rigidity associated with elasticity in distinction from solidity due to high viscosity. The word "fluidable"4 has been used to denote the potential fluidity of the earth's interior.

I Bailey Willis, "Mechanics of Appalachian Structure," I3th Ann. Rept. U.S. Geol. Surv., Part II (1893), p. 247.

${ }^{2}$ Cf. Bailey Willis, U.S. Geol. Surv., Prof. Paper No. Ig (1903), p. 97, and Joseph Barrell, Jour. Geol., XXIII (I9I5), 438. cations.

3 T. C. Chamberlin, Jour. Geol., XXVI (r918), p. I94, and personal communi-

${ }^{4}$ J. W. Gregory, Geology of Today (London, I915), p. I56. 
But in this article there is no design either to emphasize the elasticity of the earth as a whole or the liquefaction of local parts, nor on the other hand is there any need to deny the reality of these characteristics. But inasmuch as no term has yet been devised which adequately describes the character of the earth's interior, it is necessary to choose for different purposes different terms emphasizing different phases of the earth's behavior, each admissible term being complementary and not contradictory to the others.

\section{TERRESTRIAL FORCES AND CRUSTAL MEMBERS}

The nature of earth stresses. - The usual argument is that there is a more or less rigid, plastico-frangible, unshrinking crust upon a plastico-rigid, shrinking interior. Between the central sphere and its crust, adjustment is made possible by a zone of almost no strain, above which the earth's crust must undergo strain increasing from near zero at the base to a maximum at the surface. ${ }^{x}$ Within the zone of flow the strain is accommodated by flow, above that by a combination of flow and shearing. ${ }^{2}$ Any thrust that may be applied in a zone of perfect flow cannot be transmitted as such; it is transmitted hydrostatically. However, it is not probable that there is a zone of perfect flow; probably the rock yields under long-continued pressure, whereas, in the manner of tar, it might rupture under a sudden shock. Such shocks are inconceivable as affecting this zone of flow, and for purposes of this discussion the zone of flow may be regarded as one in which there is a minimum of vector or directional forces. Movement of the crust over the shrinking interior would tend to produce displacement in the zone of flow at an angle approaching zero, no matter at what angle thrust forces cause rupture in the upper crust. $^{3}$

A perfectly rigid body transmits thrust in such a way that the forces are not dissipated during transmission. This type of body does not obtain in the earth's crust, for rocks are not perfectly rigid materials. Material which is slightly plastic tends to fail near the points of the application of force instead of near the

${ }^{x}$ T. C. Chamberlin and R. D. Salisbury, Geology, II (1907), I 27-30.

${ }^{2}$ C. K. Leith, Structural Geology (1913), p. 4.

${ }^{3}$ T. C. Chamberlin, "The Problem of Faulting," Econ. Geol., II (1907), 597-99. 
center, the part most susceptible in nearly rigid members. Nevertheless, the rocks within a mile of the earth's surface are, in general, more nearly rigid in behavior than those near the zone of flow. Furthermore, there is more force to be transmitted presumably near the surface, because the length of the arc is greater at the surface than near the center, and the accumulative forces are proportional to the length of the arc to be accommodated to the shrinking. Consequently, there is a greater thrust transmitted in the rocks near the surface than through those near the zone of flow for two reasons, because the rocks are more nearly rigid, transmitting a greater proportion of the forces extant, and because near the surface there is more total horizontal force to be transmitted. These conditions may be analyzed as an unequally distributed force of the rotational type. Since the strain is greatest where relief of pressure is easiest, it follows that the strain is greater near the surface than at depth, which would result in a rotational strain even if the forces were translatory. ${ }^{x}$ Thus rotational strain results from a ready relief of pressure near the surface, and it appears reasonable that the original stresses applied also are rotational.

The length of the crustal members.-The commonly deformable crust is considered to be a discontinuous structure in the form of a supported hollow sphere composed of irregularly shaped, curved strata plates which are geographically coincident with the continental and oceanic segments. These members of the structure exert thrust forces on one another which are localized in their maximum application at the planes of contact, i.e., the borderland of continents and oceans. Roughly speaking, the members involved in the compression are as long as the continents and ocean basins are wide. The forces, however, are not of equal intensity everywhere along the length of each member; under normal conditions they are least in the center and greatest at the ends. If the earth's crust were truly rigid the intensity of thrust would be equal throughout the length of each member, each segment would serve as a footing for its neighboring segments, resulting in failure of the segments near their centers. Apparently the

I F. D. Adams and J. A. Bancroft, Jour. Geol., XXV (1917), 637; R. T. Chamberlin and W. Z. Miller, ibid., XXVI (1918), 35-37. 
members fail near their ends probably due to the fact that forces are not transmitted well through partly deformable members. The condition of a single member may be represented as in Figure I, in which it is indicated that the thrust decreases from a maximum at the edges of the continental and oceanic segments to a minimum near their centers. Part of the force is absorbed in minor deformation of the member and only part is transmitted; therefore, the increase of force toward the end of the members is not one of arithmetical progression. Thus the yielding of the earth's crust permits the stresses relief, so that at one time the intensity of

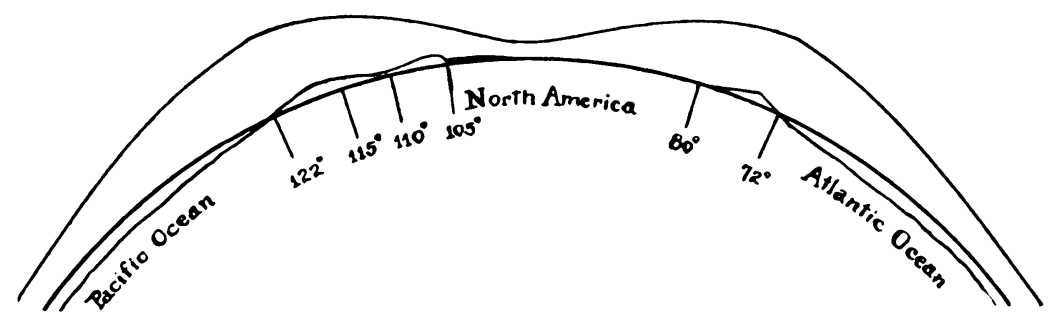

Fig. I.-Diagram to illustrate the supposed distribution of transmitted crustal stresses. The top line is supposed to represent graphically the magnitude of the transmitted stresses. The transmitted stresses vary from a minimum near the centers of the oceanic and continental segments to zones of maximum intensity near the borders of the continents.

thrust on one side of a yielding section is much greater than the intensity of thrust on the other side of the yielding section. This condition results in a movement of part of the member in the direction of the lower intensity of thrust. This direction of movement is commonly said to be the direction of the deforming force. However, action and reaction being equal and opposite, the direction of any force must be two-faced. But whatever the direction of movement, either toward or from the continental masses, the continental masses exert just as great a thrust upon the oceanic masses as they bear themselves. Consequently there must be a tendency for the oceanic masses to suffer deformation, especially near the continents. There is supposed to be a region or band of great stress at the borders both of oceanic and continental masses, within which major deformation should be expected. 
Let it be noted, however, that this band of great stress is supposed to be but a part of the total member under compression.

The depth of the crustal members.-According to Chamberlin and Salisbury ${ }^{\mathbf{x}}$ (writing in 1904) the average thickness of the folded shell is probably between three and five miles. From the context it appears that the estimate was based, in part at least, upon a reconnaissance report on the amount of uplift and shortening involved in the Appalachian folding, and the resulting figure probably should be modified especially by the results of $\mathrm{R}$. T. Chamberlin before quoted, as well as by the many contributions based upon experiments made since 1904. Heim concludes from his studies in the Alps that there the great deformations were relatively shallow in extent. In I9I2 F. D. Adams reported that open cavities might persist in rocks at depths of at least eleven miles, ${ }^{2}$ from which it appears that the zone subject to fracture and flow, or plastico-frangible deformation, might be deeper than usually expected. But from his work in association with Bancroft, ${ }^{3}$ Adams finds that the amount of thrust required to produce deformation increases rapidly with the increase in depth, and therefore concludes that the transference of material at the earth's crust must take place comparatively near the surface. Bridgman, ${ }^{4}$ who subjected metal pieces to pressures comparable to those that are supposed to obtain at depths of between twenty and seventy miles, agrees that substances tend to become more rigid under high pressures, but reports further that under great pressures there is no relation between the yield and rupture points, for there is no rupture point. Materials (metals at least) deform without rupture, although they remain highly rigid. This is the condition supposed to be characteristic of the great interior of the earth, which is therefore called plastico-rigid. ${ }^{5}$

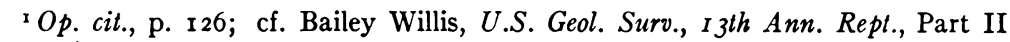
(I891-92), p. 228.

${ }^{2}$ F. D. Adams, Jour. Geol., XX (1912), 97-1 18.

3 Frank D. Adams and Austin J. Bancroft, ibid., XXV (1917), 635.

${ }^{4}$ P. W. Bridgman, Phil. Mag. (July 1912), p. 65; see also Phys. Review, XXXIV (I9I2), I-24.

${ }^{5} \mathrm{~A}$ later paper by Bridgman has further bearing on the probable plastico-rigid behavior of the interior, "On the Effect of General Mechanical Stress on the Temperature of Transition of Two Phases, with a Discussion of Plasticity," Phys. Review, New Series, VII (1916), 215-23. See also Joseph Barrell, op. cit., pp. 431-32. 
All these researches seem to indicate that the zone of fracture, folding, and of deformation in general which may be called plasticofrangible is probably confined to depths which properly may be called shallow.

T. Mellard Reade ${ }^{\mathrm{x}}$ used the terms sheet or strata-plate to describe the deformable parts of the earth's crust, and Chamberlin and Miller ${ }^{2}$ suggest that the deformation of some folded mountain chains is perhaps analogous to the deformation of a thin prism or wall.

Probably few geologists would maintain that the frangible part of the earth's crust is more than fifteen miles deep.

The probability of crustal members as such.-Thus, the crustal members are conceived to be sheets conforming to the curvature of the earth, from 200 to 300 times as wide and long as they are thick. Their proportions may be compared to those of a pavement one foot thick covering a city block about three hundred feet square. This conception of strata-plate members of great length and width might appear unreasonable were it not for the fact that each member is not an unsupported arch. Each member is very appreciably stiffened by the support of the plastico-rigid or elastico-rigid mass beneath.

A consideration of the probable effects of the yielding of such members is interesting. Supposing that there should be mountain folding near the border of a continent, the yielding decreases the stresses at the place of failure and throughout a certain distance on either side. Were the crust rigid instead of plasticofrangible, the stresses would be relieved throughout the whole of the neighboring sections, and the stress relief would be distributed promptly throughout all the members of the earth's crust. Thus, distribution of relief would tend to become world-wide, but the plastic-like behavior of the members retards such a distribution of stress and in some cases absorbs it within a relatively short distance. In such cases conditions for the continental mass may include a relieved, small, residual stress on one side of the continent and a large, almost unrelieved stress on the other side of the continent. This may result in a later break on the unrelieved

× T. Mellard Reade, The Evolution of Earth Structure (1903), p. I34.

${ }^{2}$ Op. cit., p. 2 I. 
side of the continent or may give rise to further slow adjustments affecting the major part of the continental member. In short, the mutual bearing of the crustal members upon one another may be partly responsible for the usual, very widespread epirogenic movements which follow mountain folding. These conceptions may appear at first glance to be clearly reactionary and out of accordance with modern views based on the research and studies of the last twenty years, especially with the conceptions of T. C. Chamberlin, ${ }^{\mathrm{X}}$ who discusses deep, rigid earth cones separated from one another by shear zones, but so far as is known to the writer these ideas are not necessarily in conflict with such conceptions of the earth's interior. It should be emphasized that the writer's suggestions are based on the assumption, which seems to be widely accepted, that there is a crustal member, subject to fracture and flow, separated from the underlying plasticorigid interior by a zone of shearing or flow. The recognition of this zone of separation causing the crust and the inner mass at certain times to be a discontinuous member, the parts of which are subject to separate analysis, is absolutely fundamental to this discussion. It may be that this zone of shearing is merely an occasional phenomenon coming into being only as the result of more fundamental processes, and that its depth (and in consequence its competence) may vary from time to time with different periods of stress, and it is likely that the development of such a zone to an extent comparable with the width of a continent is an extreme and unusual condition. And it must be recognized that the writer advances this study as a contribution to the analysis of low-angle faulting, in its proper relation to the other factors listed by Chamberlin and Miller $^{2}$ in the résumé of their paper previously quoted, with this difference, arising largely from the different manner of approach, that the writer would not list "length of deformed area with respect to its other dimensions (after analogy of long column)" among the minor factors, but rather among the major factors in low-angle faulting. Nevertheless, it is held to be but one of several major factors. The revision

'The Origin of the Earth (1916), chap. viii, and Jour. Geol., XXVI (rgr 8), r97.

${ }^{2}$ Jour. Geol., XXVI (1918), 44. 
of the proportions of the crustal units, the abandonment of any idea of those members being unsupported arches, the recognition that they are probably relatively temporary phenomena coming into being only upon occasion, and the limitation of this discussion to those members subject to fracture put this conception of strataplate members in an entirely different class from the old theory of crustal members which Chamberlin and Salisbury ${ }^{\mathbf{x}}$ emphatically discarded long ago.

A comparison of the crustal members with sheets and long columns. -Euler's formula ${ }^{2}$ has been used in comparing the deformation of sheetlike members of the earth's crust to the yielding and failure of long columns because the failure of sheets is similar to that of long columns and because analyses of the deformation of sheets under lateral thrust are rare or wanting. Euler's formula applies strictly only to columns having lengths many times greater than their least diameter. Of course this formula is used merely as an illustration of the order of magnitude of the strength of a sheet. It is not accurate to apply it even to every long column; yet it applies with appropriate empirical modifications to all long columns.

W. H. Burr" says: "Pieces of material subjected to compression are divided into two general classes-'short blocks' and 'long columns'; the first of these only, afford phenomena of pure compression. A 'short column' is such a piece of material, that if it be subjected to compressive load it will fail by pure compression. On the other hand, a long column (as has been indicated in Art. 25) fails by combined compression and bending. . . . . The length of a short block is usually about three times its least lateral dimension."

Therefore it is concluded that the earth's crust in major deformation follows closely the behavior of long columns because it

I T. C. Chamberlin and R. D. Salisbury, Geology, I (1904), 554-62.

${ }^{2}$ T. T. Quirke, Geol.Survey, Canada, Mcm. No. 102, "Espanola District, Ontario" (I917), p. 7r, and Chamberlin and Miller, op.cil., p. I9. According to Euler's formula the strength of a column equals

$$
E I \frac{\pi^{2}}{L^{2}}
$$

in which $E$ equals the coefficient of elasticity of the material involved, $I$ equals the moment of inertia, and $L$ equals the length of the column.

${ }^{3}$ W. H. Burr, The Elasticity and Resistance of the Materials of Engineering (1890), p. $37 \mathrm{r}$. 
appears to yield first by flexure and then by rupture, and that many experiments performed by Willis, Cadell, Chamberlin, Miller, and others, technically speaking, are experiments with long columns rather than with short blocks, because the members flexed before rupturing. More strictly speaking, most of these experiments on deformable materials fall under the mechanical analyses of neither short blocks nor of long columns because of the nature of the material, but they seem to accord the more closely to long-column analysis. If an adequate amount of experimental and analytical work had been done upon the deformation of sheets, ${ }^{\mathrm{I}}$ the writer would have used only the sheet as an illustration of earth deformation.

THE RUPTURE OF SHEETS AND LONG COLUMNS

Experiments with sheets under rotational stress.-In hope of learning more about the deformation and rupture of sheets the writer performed a few simple experiments upon easily controlled members. T. Mellard Reade has done sufficient work with straight and circumferential compression upon sheets, but the effects of a vertically unequally distributed stress heretofore have not been tried. Reade ${ }^{2}$ draws conclusions from the deformation of the lead lining of a scullery sink. The writer used a common bench vise to deform and rupture plates of soap and paraffin. Of the two, soap was the more satisfactory. In order to secure an unequally distributed stress a wedge was inserted, large end upward, between the end of the member and the face of the vise. This resulted in bringing greater pressure to bear near the top than near the bottom of the plate. If the plate had been quite free to bend it would have bent downward; however, that would not have illustrated the deformation of rock strata, and the member was therefore stiffened enough by slight pressure from below to make it bend upward. After the bending of the soap, rupture started from the bottom at a low angle from a point nearly equidistant from each

' The only work known to the writer which appears to have a bearing on the subject is "Tests of Reinforced Concrete Flat Slab Structures," by Arthur N. Talbot and Willis A. Slater, University of Illinois Bull., Vol. XIII, No. 22, I9I6.

${ }^{2} \mathrm{~T}$. Mellard Reade, The Origin of Mountain Ranges (1886), pp. 15-16, and Plate VI, p. 28. 
side, became nearly horizontal near the center, and increased to nearly $60^{\circ}$ as it approached the upper surface (Fig. 2). To prove that this is the usual type of break and not fortuitous, two more pieces of soap were flexed and broken with similar results. Two narrow pieces of soap broke with nearly vertical shear planes near

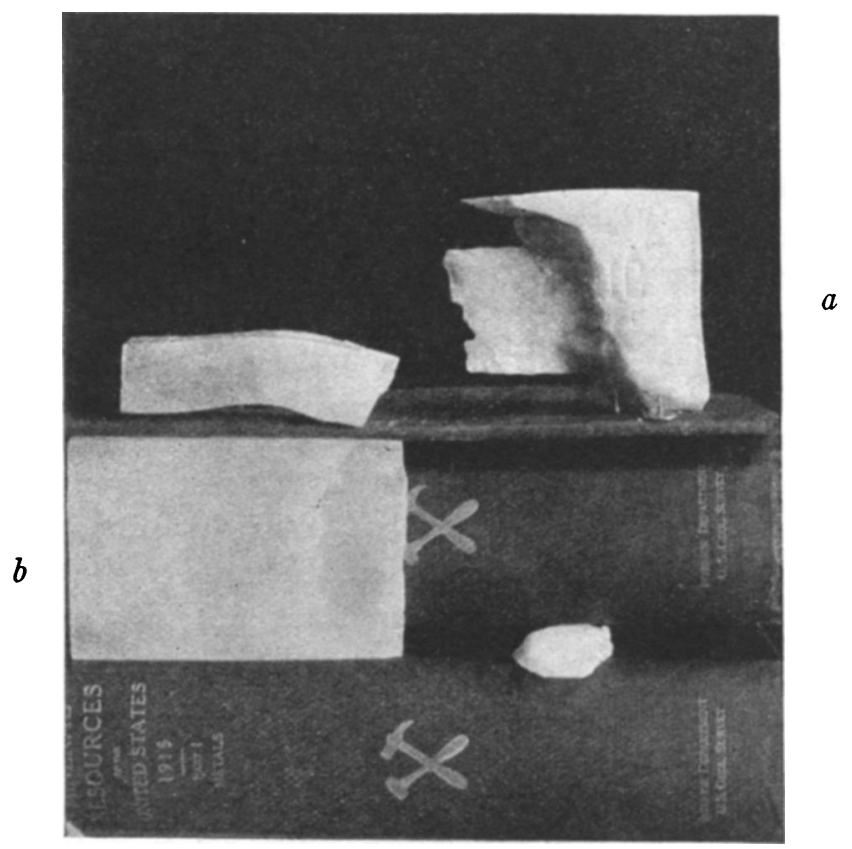

FIG. 2.-(a) A sheet of soap ruptured by combined compression and bending under rotational stress. The fault plane is high-angled near the surface and lowangled below the center of the member. These pieces are outlined in Figure 3. (b) A sheet of paraffin ruptured by combined compression and bending under rotational stress. The fault plane is almost horizontal for most of the length, changing sharply at a high angle to the surface. At one end the member is split down the center along the plane of maximum shear without actual breaking out of the piece; see also Figure 5, $(a)$ and $(b)$.

the edges (Figs. 2 and 3), but a plate wider than it is long ruptured without vertical shear planes at a low angle (Fig. 4). It seems that nearly vertical fault planes may be disregarded, occurring merely because the sheets are narrow and have lateral relief. In the case of earth deformations in general, the width of the sheet or strata-plate is probably comparable to the length of the defor- 
mation member, and vertical fault planes of a comparable origin are not commonly recognized.

Experiments with short blocks under rotational stress.-Experiments with paraffin led to somewhat different results. The

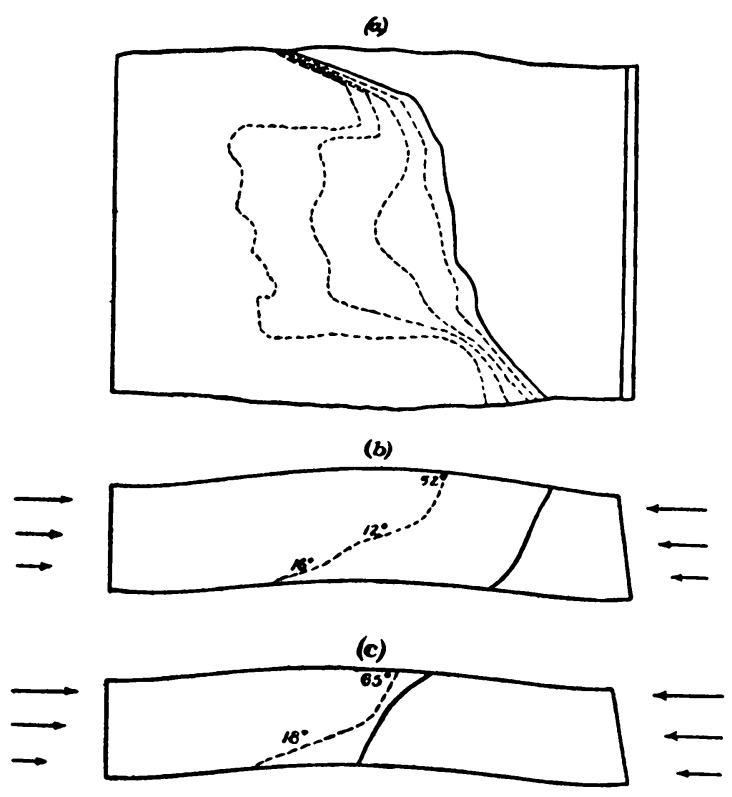

Fig. 3.- $(a)$ and $(b)$ are two views of a sheet of soap which failed by combined compression and bending under rotational stress. The dimensions of the piece of soap are ${ }_{10}^{8} \times 4 \frac{1}{2} \times 2 \frac{1}{2}$ inches. The contour intervals are ${ }_{1}^{2}$ inch, indicating the plane of rupture. A photograph of the piece is reproduced in Figure 2. (c) is a crosssection of another piece of soap showing a similar rupture. The dimensions are ${ }_{10}^{7} \times 4_{1_{10}^{2}}$ $\times 2 \frac{2}{10}$ inches.

paraffin members did not flex so readily as soap, and therefore, in spite of their dimensions, they approach the behavior of short blocks under the conditions of these experiments. The members did not break from the bottom to top but after a few preliminary high-angle slice faults part of the members seemed to chip out (Fig. 5, $c$ and $d$ ), illustrating the manner in which weak unbending blocks yield under a rotational compression. ${ }^{x}$ However, having

${ }^{x}$ In experimental engineering any cement block which is loaded with an unequally distributed load fails by breaks, making low angles with the direction of applied force. Such breaks are considered faulty, because the object of that work is to determine the strength of the blocks under equally distributed stress. 
flexed slightly, one paraffin member started to split down the center along a plane parallel to the surface in the manner of a bending column (Figs. 5 and 2 ).

Chamberlin and Miller ${ }^{\mathrm{I}}$ had obtained similar low-angle breaks when they caused rotational strain in a paraffin short block, thereby proving their contention in favor of the importance of rotational strain as a cause of low-angle faulting. The writer

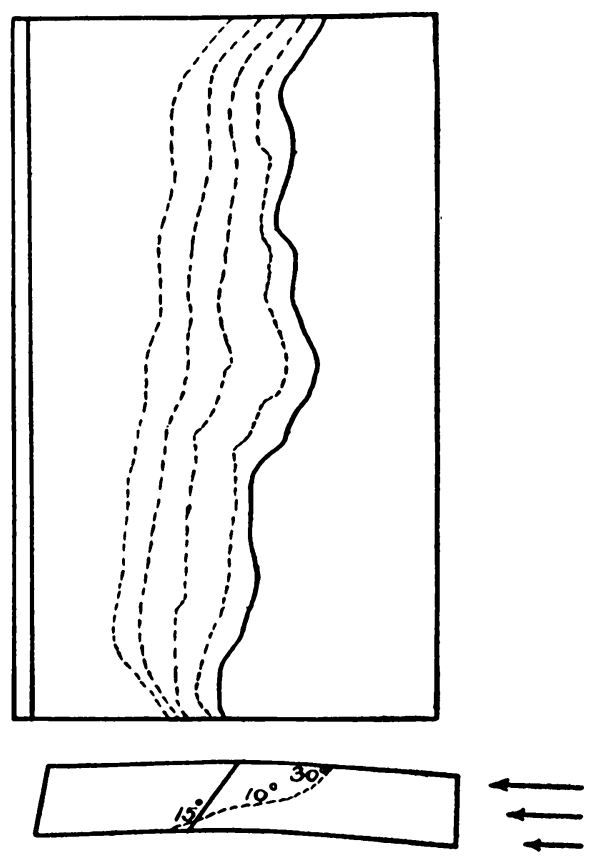

Fig. 4.-A wide sheet of soap which failed under rotational stress by combined compression and bending. The dimensions of this piece are $21_{1}^{4} \times{ }_{4} \times{ }_{1}^{4} \mathrm{o}$ inches and the contour lines are equidistant. They indicate the place of rupture.

has used a rotational stress and bending sheets rather than short blocks in order to be consistent in the general treatment and object of the paper and for the sake of the mechanical considerations which are treated later.

Analysis of the rupture of sheets and columns under translatory forces.-Long columns and sheets fail by bending and by rupture

I Jour. Geol., XXVI (1918), 35, and Fig. 16. 
under continued compression. A column may crumple into many folds or it may spring out into a single arch. The second case is stable for unsupported columns, but in the case of the earth's crust the formation of many folds is common. Mechanically the analysis of the stresses in one fold of a series is the same as that in a single arch. The maximum tensional stress is at the apex of the

(a)

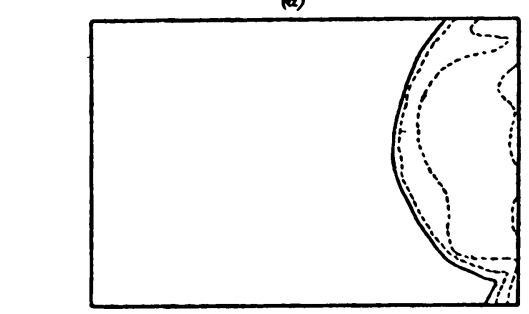

(b)

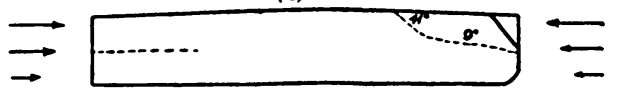

(c)
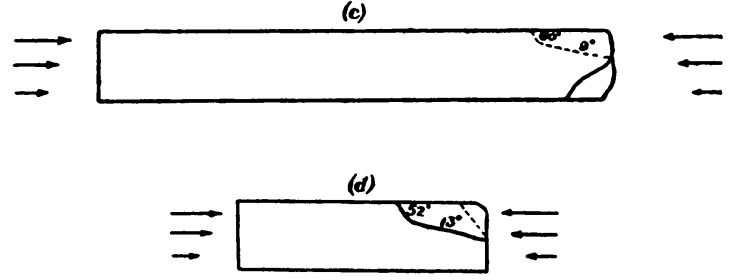

FIG. 5.-Paraffin members which failed under rotational stress. (a) and (b) are two views of a piece ${ }_{10}^{6} \times 31_{10}^{8} \times 2_{1}^{4}$ inches in size, which yielded by combined compression and bending. Compare Figure 2 and note the place of rupture along the plane of maximum shear parallel to the surface. $(c)$ is a side view of a piece ${ }_{10}^{6} \times 41_{10}^{6}$ $X_{2}{ }_{1} \mathrm{t}$ inches which seemed to fail by mere compression; the break indicated by dotted lines followed several high-angle breaks. $(d)$ is a side view of a piece ${ }_{10}^{6} \times 21_{10}^{3} \times 21_{10}^{4}$ inches in size which ruptured without flexing. Note the tendency toward highangle breaks.

arch at the surface, the maximum compression beneath the apex of the arch at the bottom of the deformed member, the focus of maximum shear a plane containing the axis of the member and parallel to the plane of greatest length and width of the member (Fig. $6 B, S-S$ ). A bending member which yields to shear alone splits from end to end along a plane of maximum shear, a similar 
member yielding to tension parts in a plane at right angles to its axis. Figure 7 illustrates the rupture of flexed wooden columns by tension and shear. Examples $A$ and $B$ have ruptured by tension and by shear, whereas example $C$ has ruptured by a combination of tension and shear. Applying these illustrations to conditions in the earth's crust, it is probable that rock is so weak to resist tension that under continued straight compression its folds are likely to rupture at the arches by tension. In the case
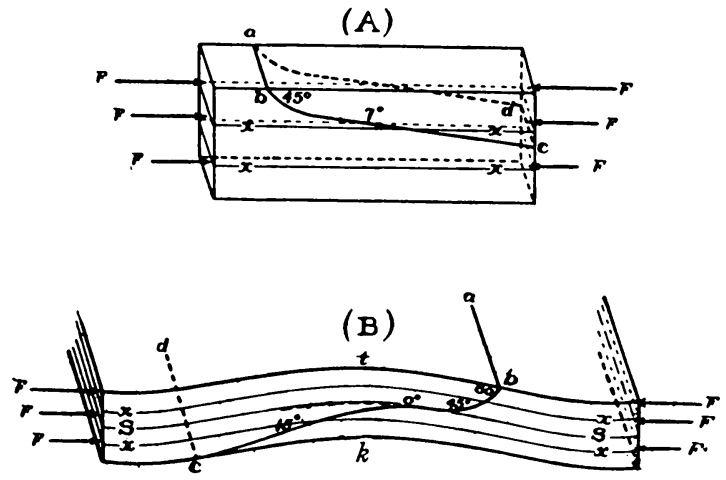

Fig. 6. $-A$ illustrates the character of rupture of a short block under highly rotational compression. The surface $a b c d$ represents the break. The planes marked $x$ represent the distributed shear due to the unequally distributed forces $F . \quad B$ illustrates the character of rupture of a long column or of a flexible sheet by rotational compression. The plane marked $S$ is the plane of maximum shear due to flexure; the planes marked $x$ indicate the planes of distributed shear and the action of the unequally distributed forces $F$. The place of maximum tension is marked $t$ and the place of maximum compression is marked $k$. The rupture $a b c d$ ideally follows the plane $S-S$ partly and emerges near $t$.

of major terrestrial deformations, however, straight compression is thought to give place to rotational forces, and the situation is changed.

Analysis of the rupture of sheets and columns under rotational forces.-Any compressive force unequally distributed in its application gives rise to shearing stresses within the member affected. The case of members folded by rotational forces includes tension due to bending, shear due to bending, and shear due to rotational stress. The plane of maximum shear is somewhere near the middle 
of the member (Fig. 6), and the tendency to shear due to rotational stress is distributed in parallel planes, one of which must coincide with the plane of maximum shear due to folding. Thus rotational stress adds a tendency to shear along the plane of maximum shear already developed by folding. This explains the low-angle breaks

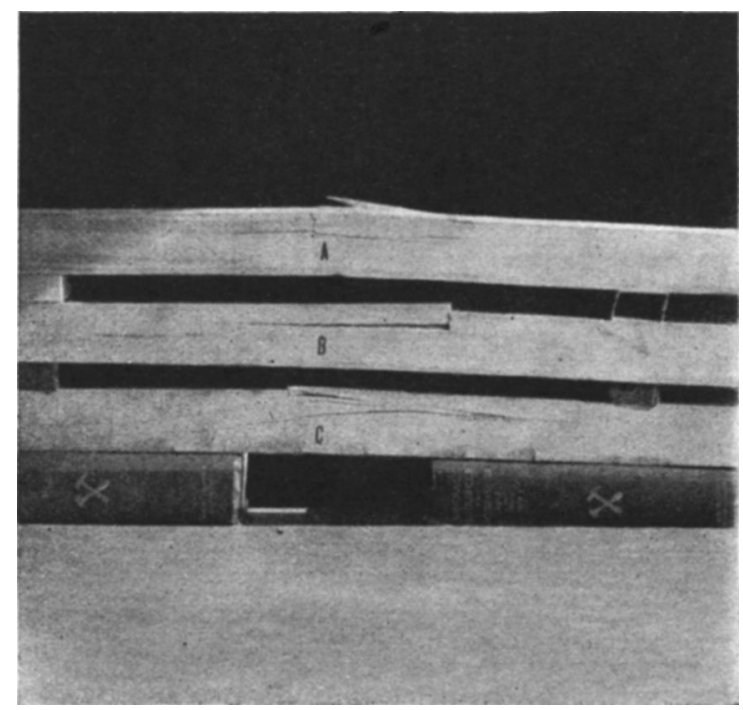

Fig. 7.- The rupture of flexed wooden columns by tension and shear. Under flexure, columns tend to split from end to end due to shearing, and to part in a plane at right angles to their long axes above the plane of shear by tension. Tension is greatest at the top of the arch, and shear is greatest along the center of the member. $A$ and $B$ show separate breaks due to shear and tension and $C$ shows rupture induced by a combination of shear and tension.

near the center of the slightly flexed paraffin sheet (Figs. 2 and 5), and the suggestion of a very low-angle break near the center of the ruptured soap (Figs. 2 and 4 ).

Contemporaneous with this tendency to shear along a plane parallel to the axis of the deformed member, there is a lesser tendency to rupture by tension. The tensional break approaches a plane normal to the top of the arch, at right angles to the plane of maximum shear (Figs. 6 and $7 A$ and $B$ ). A combination of these two is a plane which sweeps through a considerable change of 
position amounting to $90^{\circ}$ in extreme cases. Such a combination is illustrated in the breaking of one wooden piece (Fig. ${ }_{7} \mathrm{C}$ ) and in the rupture of the soap and paraffin (Figs. 2, 3, 4, and 5).

Comparisons between geological thrust deformations and members ruptured by rotational stress. - In cases where rock members are subjected to both tension and shear we expect failure to be due to that which the rock is least able to withstand, that is, a combination of both shear and tension. Rocks are strong to resist compression, and failure of rock members by straight compression needs little consideration when either great shear or great tension is involved.

Comparisons between the rupture of these members which fail by combined compression and bending, the rupture of short blocks which fail by pure compression, and the geological relations of overthrust and reverse faults seem to suggest that many thrust faults may have resulted from the yielding of flexed members which have failed along planes of shear and tension, members of the class of long columns.

Thus it appears that some members under terrestrial compression are curved sheets or strata-plates, which are thin in comparison with their width and length; being subjected to an unequally distributed rotational stress they break normally along shear planes of low angles at depths which steepen to high angles due to tension near the surface.

\section{KINETICS OF THRUST FAULTING}

Analysis of the conditions following rupture and preceding displacement.-Some rotational force deforms the terrain by flexure. If the folding is sharp no fold can transmit thrust because the fold must fail at the crown of the arch due to localized tension. Rock is incompetent to carry tensional stresses, and therefore a high arch fails under lateral compression. If the arch fails, no appreciable thrust can be transmitted until folding has reached an isoclinal condition, involving great shortening, great thickening, and thereby great strengthening of the member. ${ }^{\mathrm{I}}$ This case is extreme and must be rare. More commonly the folds are so low that thrust

${ }^{\prime}$ Cf. Quirke, op. cit., p. $7^{2}$. 
can be transmitted without rupture of the arches, and rupture follows the forms outlined above (Fig. 6). In an analysis of the conditions at the instant after rupture, let $P$ be the total compressive force, let $C$ be the weight of the moving mass, let $\theta$ be the angle of shearing at any one place, and let $a$ represent the crosssectional area of the member. Then, as Chamberlin and Miller show, ${ }^{\mathrm{I}}$ the intensity of thrust $\left(p_{t}\right)$ tangential to the shear plane is

$$
p_{i}=\frac{P \sin \theta \cos \theta}{a}
$$

and the intensity of the normal stress $\left(p_{n}\right)$ is

$$
p_{n}=\frac{P \sin ^{2} \theta}{a}
$$

Likewise, the force of gravity is resolved into tangential and normal components, the tangential opposing the tangential component of the thrust, and the normal being added to the normal component of the thrust. The tangential component of gravity is

$$
G_{\iota}=G x \sin \theta,
$$

and the normal component is

$$
G_{n}=G x \cos \theta .
$$

The intensity of the tangential component of gravity is

$$
g_{t}=\frac{G \sin \theta}{a \cot \theta}=\frac{G}{a} \sin \theta \tan \theta .
$$

The intensity of the normal component of gravity is

$$
g_{n}=\frac{G \cos \theta}{a \cot \theta}=\frac{G}{a} \sin \theta .
$$

Thus, after rupture the intensity of thrust becomes

$$
\frac{P \sin \theta \cos \theta \quad G \sin \theta \tan \theta}{a}=\frac{\sin \theta}{a}(P \cos \theta-G \tan \theta),
$$

and the intensity of friction becomes

$$
\mu\left(\frac{P \sin ^{2} \theta}{a}+\frac{G}{a} \sin \theta\right)=\mu \frac{\sin \theta}{a}(P \sin \theta+G),
$$

in which $\mu$ represents the coefficient of kinetic friction.

${ }^{\prime}$ Jour. Geol., XXVI (1918), I5 ff. 
In order to achieve displacement,

$$
\frac{P \sin \theta \cos \theta}{a}
$$

must be sufficiently greater than

$$
\frac{G \sin \theta \tan \theta}{a}
$$

to overcome the friction due to both the normal component of thrust and the normal component of gravity. The friction will become less per square unit of fault plane as slickensides and other smooth surfaces are developed by movement. But the total area of friction increases with displacement, and it follows from the preceding formulas that friction is greatest in intensity where $\theta$, the angle of displacement, is greatest.

The fault plane decreases in steepness as displacement increases.Rupture being accomplished, as indicated in Figure $6 B$, the fault plane varies from places of low dip far beneath the surface to places of high dip nearer the surface. Where the angle is low the tangential thrust is greatest, the normal component of thrust is least, but the normal component of gravity is a maximum, and the resistant, tangential component of gravity is a minimum. Near the surface where the angles are high and the normal component of gravity is low, the resistant tangential thrust due to gravity is a maximum and the tangential component of the compressive force is a minimum, but its frictional component is a maximum. In all these movements the compressive thrusts must be dominant, otherwise the force of gravity and friction would prevent displacement. Therefore, displacement being granted, the effect of gravity is not vital in the discussion. Obviously, then, the effects of thrust result in a maximum shear along low-angled planes and a maximum friction at high-angled planes.

In the general case of rupture represented in Figure $6 B$ maximum friction is near the surface. The hanging wall of millions of tons of rock moving several miles along this fault plane will result in enormous abrasion, much as a glacier abrades greatly the stoss sides of steep opposing hillsides, and this abrasion will be greatest 
where friction is greatest, at the steepest part of the plane, affecting both the footwall and the hanging wall. During early displacement the fault will appear at the surface as a steeply dipping plane; by the time displacement has continued for a mile, the angle of the fault plane must have been worn flatter by the friction of the moving load; finally, by the time displacement has attained a few miles, the low-angled sole will have reached the surface, and the fault plane must have been reduced to a low angle by abrasion, leaving no trace of the steep parts of the original break.

In this manner it is suggested that all great thrust faults which are steep-angled near the surface, if persistent in depth, follow the low-angle form at the depth of a few miles, and that in a general case the angle of faulting at the surface may depend as much upon the amount of displacement subsequent to rupture as upon fundamentally different conditions in the application of earth forces or in the character of the members affected. In support of this it may be recalled that, so far as is known regarding thrust faults, all faults of great displacement have low-angle fault planes, and no faults of high angles exceed a few miles in displacement.

Willis ${ }^{\mathrm{I}}$ has described rotated, high-angle thrust faults of relatively small throw in the coast ranges and the Sierra Nevada, which he considers to have some such shape as is here suggested for thrust faults of small displacement; however, his explanation of their character differs considerably from the general argument of this paper.

\section{CONCLUSION}

In conclusion some repetitions seem pertinent. Certain parts of the earth's crust which are deformed by regional compression are held to be analogous to sheets and comparable in mechanical analysis to long columns. The normal terrestrial stress is said to be an unequally distributed thrust of rotational type. The transmission of stress as a vector quantity supposedly extends from the surface to a depth scarcely exceeding fifteen miles. There is a zone of potential separation between the frangible crust and the rigid interior which is nearly parallel to the surface. In some cases thrust faults of very great displacement may be extensions

'Bailey Willis, Geol. Soc. Amer. Bull., XXX (Igrg), 84-86. 
of this low-angle zone of parting to the surface at an increasing degree of steepness; ${ }^{\mathrm{r}}$ in other cases rupture occurs within the bending part of the crust near the plane of maximum shear with a break low-angled at depth and increasing in steepness near the surface. In either case displacement of less than one mile results in a steep-angle fault, an ordinary reverse fault, but displacement of several miles results in reduction of steepness of the fault plane by the abrasion of the footwall and by advancement of the lowangle part of the hanging wall to the surface. Thus some low-angle overthrust faults and high-angle reverse faults may represent different stages of a single process.

× T. C. Chamberlin, Econ. Geol., II (I907), 597-99. 